\title{
"Shutdown", "Reconducción". Herramientas presupuestarias de los Estados Unidos de América y la República Argentina
}

\section{POR MÓNICA BARIGGI $(*)$}

\begin{abstract}
Sumario: I. Introducción.- II. Ciclo del presupuesto público y la sanción presupuestaria.- III. Reconducción.- IV. Shutdown.- V. Conclusión.- VI. Bibliografía.
\end{abstract}

Resumen: la gestión y el control de la actividad financiera del Estado se plasma en la ley de presupuesto. En la mayoría de los Estados del mundo es necesaria una ley financiera periódica. Ahora bien, ¿qué sucede cuando no se logra el consenso en el Congreso para llegar a aprobar esa ley? Ante el interrogante descripto se presentan dos modelos de herramientas con diferentes consecuencias políticas y económicas financieras: por un lado, el modelo del "shutdown" de la administración utilizado en Estados Unidos de América y por el otro la "reconducción" presupuestaria en uso en la República Argentina.

Palabras claves: shutdown - reconducción - presupuesto público

\section{"Shutdown", "Renewal". Budget tools in the United States of America and the Republic of Argentina}

Abstract: the budget law establishes the management and control of the financial activity in a Country. Most countries in the world need a periodic financial law to perform their (basic) functions. However, what happens if Congress cannot reach an agreement to pass a budget law? In that scenario, there are two different models that generate their own economic and financial consequences: On the one hand, there is a government "shutdown" in the United States and on the other a budget "renewal" in the Republic of Argentina.

Keywords: shutdown - renewal - budget

$\left({ }^{*}\right)$ Prof. Adjunta Interina Finanzas y Derecho Financiero Cátedra III, Facultad de Ciencias Jurídicas y Sociales, Universidad Nacional de La Plata, UNLP. 


\section{Introducción}

Es sabido que la actividad financiera del Estado resulta ser la coordinación económica activa de bienes y personas, en un espacio territorial determinado con el fin de satisfacer necesidades comunes y colectivas, conforme a un régimen de subordinación de la autoridad pública, de naturaleza delegada. Se puede enumerar rápidamente una serie de característica propias de la actividad financiera tales como la de ser una actividad compulsiva (no voluntaria), perdurable (no transitoria), directa (se aplica inmediatamente a la atención de las necesidades), es una actividad administrativa (no especulativa), es ejercida sobre límites territoriales (derivado de características del concepto Estado); es formal (en tanto la administración pública se encuentra reglada); es política; y por último y no por ello menos importante, la gestión y control de la actividad financiera bajo análisis tienen origen y giran en torno al presupuesto.

Debe remarcarse que el presupuesto se presenta en los Estados como una ley, como el acto legislativo en el que son previstos y autorizados los gastos y los recursos anuales o periódicos del Estado y por el cual se gestiona, se proyecta y se visualiza públicamente, la actividad financiera del Estado tratando de sintetiza el plan de gobierno del ejercicio financiero próximo.

En este marco, el ciclo del presupuesto que refleja la actividad financiera, guarda una dinámica propia conformado por las fases de elaboración, sanción, ejecución y control, el presupuesto es una ley cuyo proyecto es elaborado en muchas áreas de la administración púbica, elaborado y coordinado por el Poder Ejecutivo y requiere el tratamiento en el Poder Legislativo para su aprobación y su puesta en marcha.

El interrogante que se pretende analizar aquí se centra en desentrañar qué sucede cuando el Poder Legislativo no logra - por diversos motivos — aprobar la ley de presupuesto para el ejercicio financiero inmediato próximo.

Las soluciones que los Estados han implementado mediante las normas de administración financiera propias para hacer frente a la continuidad de la actividad económica pública gestionada a través del presupuesto se vinculan a dos soluciones antagónicas: o se sigue con la actividad financiera a pesar de no haber alcanzado una ley de presupuesto, o por el contrario se paraliza la administración pública hasta tanto se llegue a aprobar la ley de presupuesto. Estas dos opciones conllevan la creación e implementación de dos mecanismos concretos: a) la "reconducción”, esto es la continuidad de la ley de presupuesto vigente y b) el "shutdown", esto es el cierre de la administración hasta lograr el acuerdo en el Poder Legislativo.

En este marco planteado el presente trabajo intenta abordar el análisis del instante en que el Poder Legislativo no logra alcanzar el acuerdo necesario para continuar con la dinámica de la actividad financiera estatal. Se trata del estudio 
de una herramienta que se encuentra en la etapa de sanción presupuestaria, que conforme se diseña este ciclo presupuestario los diferentes Estados han adoptado la modalidad de "shutdown" o de "reconducción".

\section{Ciclo del presupuesto público y la sanción presupuestaria}

Hablar de "ciclo" presupuestario implica sostener la idea de periodicidad en la dinámica de la administración financiera vinculado al elemento temporal en el que se desarrolla el ejercicio financiero un Estado. Básicamente es expresado por la doctrina en cuatro momentos, las etapas o fases temporales en las que se divide el ciclo presupuestario. Ellas son: preparación presupuestaria, etapa de sanción presupuestaria, ejecución presupuestaria por parte del Poder Ejecutivo y por último el control presupuestario interno y/o externo - conforme el diseño de control financiero diseñado por el Estado- (Giuliani Fonrouge, 2004).

Las etapas enumeradas se corresponden una a otra en una consecución de hechos y actos concatenados que se desarrollan uno tras otros y algunos al mismo tiempo en que se encuentran desarrollándose otros; por ejemplo, puede coincidir la etapa de ejecución presupuestaria con la de control (para el caso de control interno a priori) con la de elaboración o preparación presupuestaria. Pueden coincidir etapas, pero nunca bajo ningún modelo o diseño de actividad financiera, eliminarse estas fases. Consecuentemente, esta condición "dinámica" del presupuesto abarca no sólo al ciclo presupuestario, sino que se extiende a la vinculación del presupuesto con la actividad general de la Nación no sólo con la economía sino con la vinculación de esta norma con los problemas de comercio local e internacional, pagos internacionales, pobreza, salarios, ingresos, moneda y crédito entre tantos otros. Surge entonces el presupuesto como el instrumento técnico organizador concebido como control de la contabilidad central al servicio de una red general de previsión y planificación económica, como un instrumento económico, político y social indispensable en el que confluye la síntesis de los objetivos financieros y políticos del Estado (Giuliani Fonrouge, 2004).

Sabido es que bajo la misma órbita doctrinaria se establece que el presupuesto es una ley formal, un plan contable del Estado, en tanto resulta ser un programa financiero elaborado por el Poder Ejecutivo y el Poder Legislativo aprueba o autoriza, facultado al primero para gestionar los ingresos y gastos preestablecidos.

Ahora bien, para algunos autores no se trata la ley de presupuesto de un acto jurídico simple, en tanto es el resultado de una mezcla de actos jurídicos reunidos en un solo documento. En esta posición de Jèze se puede observar un criterio restrictivo respecto de las facultades del Poder Legislativo limitadas a la autorización de la gestión financiera del Estado, desempeñando una función secundaria por el 
voto o sanción del presupuesto, dan al documento la exterioridad formal de los actos administrativos (Giuliani Fonrouge, 2004).

Ante tal afirmación Fonrouge gravita en considerar que la función legislativa en la República Argentina es importante y no se reduce a aprobar o autorizar lo dispuesto por el ejecutivo. Bajo este razonamiento doctrinario se trata de una ley normal no de un mero acto aprobatorio, así, la acción parlamentaria es normal primordial y básica, originaria y no derivada o subordinada, en estas características radica que la Sanción Presupuestaria resulte ser un acto complejo de relevancia fundamental en el ciclo presupuestario (Giuliani Fonrouge, 2004). Bajo la influencia de esta última posición doctrinaria se analizará más adelante la influencia de la "reconducción" presupuestaria en el marco de la etapa de sanción presupuestaria a fin de dar una respuesta al interrogante planteado supra.

En cuanto al análisis del ciclo presupuestario mediando la activación del mecanismo del shutdown desde las normas financieras de Estados Unidos de América involucra el cierre de la administración pública hasta llegar al acuerdo en el Congreso necesario para aprobar la ley de presupuesto. Consecuentemente, es bajo la implementación de este instrumento que parece surgir el verdadero sentido de ley formal, en tanto que el paso por el Poder Legislativo no resulta ser un mero acto aprobatorio, sino todo lo contrario parece cobrar relevancia la intervención del Poder Legislativo en la etapa de sanción presupuestaria. En tanto que si éste no logra el acuerdo necesario no hay ley presupuestaria y se cierra toda actividad pública estatal.

Habiendo desarrollado la dinámica de la actividad presupuestaria corresponde ahora analizar el momento final de la fase de sanción presupuestaria la cual según corresponda la legislación podrá tratarse de reconducción o de shutdown.

\section{Reconducción}

Tal como fuera adelantado, la falta de sanción de esta ley de presupuesto a la fecha prevista por las normas financieras generales genera la activación del mecanismo de reconducción. Este mecanismo posee la finalidad de minimizar las consecuencias de no contar con una ley financiera aprobada al iniciar un año fiscal. La figura de la reconducción presupuestaria, aparece como una herramienta legal que pretende solucionar esta situación de falta de acuerdo político. La adopción de cualquier modalidad de reconducción esencialmente tiene como objetivo atenuar los efectos derivados del incumplimiento de los plazos establecidos para la aprobación del presupuesto anual (Sleman Valdés - López Lara, 2013).

Se trata así, de establecer una herramienta "excepcional", un mecanismo "extraordinario", de carácter provisional o permanente (conforme el modelo de 
reconducción adoptado por las normas financieras estatales) cuya finalidad es enfrentar una situación de impasse. Si el mecanismo de reconducción seleccionado en "temporal" la reconducción culminará al momento de la aprobación de la ley de presupuesto, contrariamente a lo que más adelante se analizara como shutdown. La reconducción opera como una "red de protección" en caso de que el presupuesto correspondiente al ejercicio fiscal anual no sea aprobado en tiempo $\mathrm{y}$ forma.

Este sistema de protección que se está analizando se centra en el otorgamiento de viabilidad financiera al gasto público, al permitirle de manera amplia o acotada seguir cumpliendo y desarrollando los fines del Estado. Esta forma asegura la continuidad en la prestación de los servicios públicos (esenciales o no), la consecución de los programas y proyectos de gobierno y de inversión, así como también el pago de deuda pública asumida que de otra forma se verían totalmente paralizadas ante la falta de una autorización legal y formal para gastar y ejercer la disposición de los recursos públicos.

Los modelos de reconducción que pueden plantearse en las distintas normas que diseñan la dinámica de la administración financiera son diversos, ello conforme a los diferentes aspectos del diseño de este mecanismo basado en el elemento temporal de vigencia de la reconducción, sobre las áreas o proyectos presupuestario reconducidos.

En este sentido, cuando el modelo de reconducción del presupuesto se encuentra bajo el elemento "tiempo" se sostiene que la reconducción puede ser: a) temporal: mediante el cual las normas de reconducción plantean este mecanismo por un plazo determinado, o cuando se logre el acuerdo del Congreso o b) permanente: en este caso la reconducción rige en el plazo de vigencia del período financiero que se trate, tal como sucede en el diseño del instituto bajo estudio en Argentina (Sleman Valdés; López Lara, 2013).

En este orden de ideas, cuando se diseña el mecanismo de la reconducción, puede ser "parcial" en tanto puede tomarse como eje la continuación de algún plan, proyecto o programa específico que de acuerdo con los parámetros legales y/o financieros, políticos o sociales sean necesarios sostener activos y vigentes y dejar sin reconducir los restantes programas, acciones o proyectos de gobierno. Por su parte, en la reconducción "total" presupuestaria surge que la totalidad de la ley presupuestaria del ejercicio financiero inmediato se traslada a la próxima ley reconducida, sin efectuar excepciones. 


\section{Cuadro No 1. Esquema de clasificación de "reconducción" presupuestaria}

\begin{tabular}{|l|l|}
\hline Reconducción Temporal & Reconducción hasta lograr acuerdo en Congreso. \\
\hline $\begin{array}{l}\text { Reconducción } \\
\text { Permanente }\end{array}$ & $\begin{array}{l}\text { Reconducción durante todo el período financiero } \\
\text { próximo. }\end{array}$ \\
\hline Reconducción Total & Reconducción de toda la ley de presupuesto. \\
\hline Reconducción Parcial & Reconducción de programas o proyectos de la ley. \\
\hline
\end{tabular}

Fuente: elaboración propia con base en ley No 24.156, Fonrouge, 2004; Sleman Valdés; López Lara, 2013.

Llegar a la utilización de esta herramienta es consecuencia directa de los posibles desacuerdos y posicionamientos políticos sobrevinientes de las distintas coyunturas sociopolíticas que atraviesa cada Estado en el proceso de creación de la ley de presupuesto. O por el contrario, no habiendo alcanzado este consenso de poder político dentro del congreso o las legislaturas, el precepto que debe mantenerse bajo esta herramienta es: gobernar para poder seguir la gestión de la administración financiera y el planteo del diseño del mecanismo de la reconducción tiende a generar ciertos beneficios vinculados al aspecto financiero en tanto permiten esta continuidad económica financiera, por ejemplo la reconducción tiende a prorrogar la vigencia del presupuesto inmediato anterior, manteniendo la dinámica de las finanzas públicas y en especial del presupuesto (Sleman Valdés; López Lara, 2013).

En países emergentes como el caso de la República Argentina, con grandes y constantes conflictos sociales y económicos enmarcados en una alta tasa de pobreza que se encuentra reflejada en los números del presupuesto anual; el evitar el cierre de programas esenciales vinculados por ejemplo a la asistencia social, educación, salud y otros como pago de servicio de deuda externa, a fin de sortear el cierre (total o parcial) de la administración pública, permite al gobierno que gestiona seguir en funciones, continuar trabajando e impedir al menos conflictos sociales y económicos mayores, posicionándose como una verdadera herramienta de protección social en Estados altamente vulnerado en este aspecto.

Finalmente dependiendo del diseño del instituto bajo estudio se pueden elaborar herramientas de reajustes económicos financieros en coyunturas variables para implementar la reconducción en forma real, en tanto pueden reajustarse parámetros inflacionarios, paritarias, contextos de variable internacional con impacto en la balanza comercial, parámetros monetarios, etc., que deben analizarse para la continuidad presupuestaria.

Sin perjuicio de las bondades reseñadas, el mecanismo analizado se activa cuando no se lograr (momentánea o definitivamente) el acuerdo consenso político general. En el caso de la reconducción permanente debe soslayarse que se extiende en su vigencia a todo el ejercicio financiero y no obliga a llevar a un acuerdo para lograr generar la ley de presupuesto. Esto es una situación altamente 
desventajosa para poder seguir adelante con la gestión que realizará el Poder Ejecutivo en forma unilateral y durante todo el ejercicio financiero futuro.

De esta forma la obligatoriedad de la continuidad de la actividad financiera y del ciclo presupuestario parece determinar que no resulta ser relevante el rol del Poder Legislativo en la etapa de sanción presupuestaria, en tanto se llegue a un acuerdo o no en la sanción de la ley, el Poder Ejecutivo seguirá con el ciclo presupuestario en marcha.

Debe destacarse el peligro que adquiere que esto se transforme en una herramienta de uso ordinario por los gobiernos en tanto que existen modelos de reconducción mediante los cuales el ejecutivo adquiere al momento de la reconducción presupuestaria, el poder para efectuar los ajustes y reacomodamientos necesarios para llevar adelante este mecanismo. Así en países, como es el caso bajo análisis, en donde existen altos índices de inflación anual, los reajustes se darán en forma unilateral por el Poder Ejecutivo, sin control ni acuerdo político del congreso nacional al momento de su estimación.

A continuación, se exponen en forma esquemática las ventajas y desventajas de la implementación de la reconducción:

\section{Cuadro No 2}

\begin{tabular}{|l|l|}
\hline \multicolumn{1}{|c|}{ Reconducción desventajas } & \multicolumn{1}{|c|}{ Reconducción ventajas } \\
\hline $\begin{array}{l}\text { - Herramienta unilateral - pérdida de rele- } \\
\text { vancia del rol del Poder Legislativo. El Poder }\end{array}$ & $\begin{array}{l}\text { - Herramienta de protección social: evita el } \\
\text { cierre de programas esenciales como los so- } \\
\text { ciales, de salud, educación. }\end{array}$ \\
$\begin{array}{l}\text { Ejustes y reacomodamiento presupuestario } \\
\text { en forma unilateral, la aprobación por parte } \\
\text { del Poder Legislativo parece convertirse en } \\
\text { una mera autorización. }\end{array}$ & \\
\hline $\begin{array}{l}\text { - Mecanismo sin control inmediato frente a } \\
\text { los ajustes y readecuación: no hay control ni } \\
\text { conceso de la actividad financiera, en tanto } \\
\text { los ajustes y readecuaciones son efectuados } \\
\text { por el Poder Ejecutivo. }\end{array}$ & $\begin{array}{l}\text { - Mecanismo por sobre las coyunturas po- } \\
\text { pública, otorga una continuidad financiera- } \\
\text { económica a pesar de las coyunturas políti- } \\
\text { cas temporales. }\end{array}$ \\
\hline $\begin{array}{l}\text { - Obligatoriedad de continuidad financiera: } \\
\text { se transforma en un mecanismo obligatorio } \\
\text { (no opcional o facultativo) para la continui- } \\
\text { dad económica financiera. }\end{array}$ & $\begin{array}{l}\text { - Herramienta de continuidad: permite al } \\
\text { gobierno en funciones seguir trabajando/ } \\
\text { gestionando. }\end{array}$ \\
\hline $\begin{array}{l}\text { - El uso frecuente genera efecto negativo: } \\
\text { como herramienta de uso ordinario, se tor- } \\
\text { na un mecanismo negativo en tanto la dis- } \\
\text { crecionalidad de un poder y falta de acuerdo } \\
\text { general. }\end{array}$ & $\begin{array}{l}\text { - Permite ajustes en contextos financieros } \\
\text { variables: dependiendo el tipo de reconduc- } \\
\text { ción puede ser considerandos los ajustes } \\
\text { económicos que, por fenómenos como la } \\
\text { inflación, pudieran afectar la ley de presu- } \\
\text { puesto reconducido. }\end{array}$ \\
\hline
\end{tabular}




\section{Reconducción desventajas}

- No hay acuerdo político: en el caso de reconducción permanente, no hay acuerdo político, no hay consenso en el congreso.
Reconducción ventajas

- Herramienta que mantiene la dinámica de la administración financiera: prórroga la vigencia del presupuesto inmediato anterior, manteniendo la dinámica de las finanzas públicas y en especial del presupuesto.

Fuente: elaboración propia con base en ley No 24.156, Fonrouge, 2004 y Sleman Valdés; López Lara, 2013.

\section{III.1. La norma de reconducción en la República Argentina}

Conforme lo establece el artículo 10 de la Ley de Administración Financiera Nacional - No 24.156- (complementarias y modificatorias) el período financiero de la Administración Pública de la República Argentina se extiende desde el 1 de enero al 31 de diciembre de cada año. Consecuentemente, uno de los últimos pasos de la etapa de sanción presupuestaria en la República Argentina conlleva la aprobación por parte del Congreso Nacional de la Ley de Presupuesto antes del último día de vigencia del presupuesto anterior, esto es al 31 de diciembre de cada año, el Congreso Nacional debe aprobar la ley de presupuesto que regirá para el año siguiente (artículo 27 de la ley No 24.156). El proyecto de ley de presupuesto que debe aprobarse corresponde al proyecto presentado por el Poder Ejecutivo ante el Poder Legislativo antes del 15 de septiembre del año anterior que va a regir como ley de presupuesto conforme lo establece el artículo 26 de la ley No 24.156.

Debe recordarse que es desde 1992 con la sanción de la Ley de Administración Financiera Nacional el ejecutivo comenzó a presentar el proyecto de ley frente Poder Legislativo en tiempo y forma conforme lo exige la ley referida, situación que antes de su creación no resultaba respetada por el Poder Ejecutivo. Asimismo, al 31 de diciembre del año anterior a regir, el proyecto enviado debe encontrarse aprobado por el Poder Legislativo de no ser así la norma que define la dinámica de la administración financiera de la República Argentina prevé facultar al Poder Ejecutivo a realizar una serie de ajustes presupuestarios sobre el presupuesto de la ley del año anterior con la finalidad de garantizar la continuidad y eficiencia de los servicios propios del Estado. Estas facultades del Poder Ejecutivo en cuanto a los recursos se refiere a eliminar los rubros de recursos que no puedan ser recaudados nuevamente, suprimir los ingresos provenientes de operaciones de crédito público autorizadas, en la cuantía utilizadas; excluir los excedentes de ejercicios anteriores correspondientes al ejercicio financiero anterior, en el caso que el presupuesto en proceso de ejecución hubiera previsto su utilización, debiéndose estimar cada uno de los rubros de recursos para el nuevo ejercicio y por último incluir los recursos provenientes de operaciones de crédito público en ejecución, cuya percepción se prevea en el ejercicio. 
Por su parte, el Poder Ejecutivo en cuanto a los gastos puede: eliminar los créditos presupuestarios que no deban repetirse, incluir los créditos presupuestarios indispensables para el servicio de la deuda y las cuotas que se deban aportar en virtud de compromisos asumidos; incluir los créditos presupuestarios indispensables para asegurar la continuidad y eficiencia de los servicios; y por último adaptar los objetivos y las cuantificaciones en unidades físicas de los bienes y servicios a producir.

Agregándose que luego de la modificación del año 2009 del artículo 42 de la ley No 24.156 se establece que los gastos comprometidos y no devengados al 31 de diciembre de cada año se afectarán automáticamente al ejercicio siguiente, imputando los mismos a los créditos disponibles para ese ejercicio. Los gastos devengados y no pagados al 31 de diciembre de cada año podrán ser cancelados, durante el año siguiente, con cargo a las disponibilidades en caja y bancos existentes a la fecha señalada y finalmente los gastos mencionados también podrán ser cancelados, por carácter y fuente de financiamiento, con cargo a los recursos percibidos en el ejercicio siguiente.

El modelo de reconducción planteado por la norma argentina infiere una "reconducción" establecida en forma total. Esto supone que se reconduce no solo programas sino toda la ley de presupuesto del año en curso, esto vincula al período financiero señalado en la norma (ley No 24.156) estableciéndose que la reconducción presupuestaria se instaurará entonces desde el $1^{\circ}$ de enero al 31 de diciembre del año a regir, en tanto este es el período financiero estipulado en la norma argentina.

A continuación, se acompaña un breve esquema sobre las facultades del Poder Ejecutivo frente a la "reconducción" presupuestaria en la República Argentina:

\section{Cuadro No 3}

\section{Facultades del Poder Ejecutivo en la reconducción sobre los "recursos"}

a. Eliminar los rubros de recursos que no puedan ser recaudados nuevamente.

b. Suprimir los ingresos de operaciones de crédito, público autorizadas, en la cuantía en que fueron utilizadas.

c. Excluir los excedentes de ejercicios anteriores correspondientes al ejercicio financiero anterior, en el caso que el presupuesto que se está ejecutando hubiera previsto su utilización.
Facultades del Poder Ejecutivo en la reconducción sobre los "gastos"

a. Eliminar los créditos presupuestarios que no deban repetirse por haberse cumplido los fines para los cuales fueron previstos.

b. Incluir los créditos presupuestarios indispensables para el servicio de la deuda y las cuotas que se deban aportar en virtud de compromisos derivados de la ejecución de tratados internacionales.

c. Incluir los créditos presupuestarios indispensables para asegurar la continuidad y eficiencia de los servicios. 


\begin{tabular}{|l|l|}
\hline $\begin{array}{l}\text { Facultades del Poder Ejecutivo en la } \\
\text { reconducción sobre los "recursos" }\end{array}$ & $\begin{array}{l}\text { Facultades del Poder Ejecutivo en la } \\
\text { reconducción sobre los "gastos" }\end{array}$ \\
\hline $\begin{array}{l}\text { d. Estimar cada uno de los rubros de recur- } \\
\text { sos para el nuevo ejercicio. }\end{array}$ & $\begin{array}{l}\text { d. Adaptar los objetivos y las cuantificacio- } \\
\text { nes en unidades físicas de los bienes y servi- } \\
\text { cios a producir por cada entidad, a los recur- } \\
\text { sos y créditos presupuestarios que resulten } \\
\text { de los ajustes anteriores. }\end{array}$ \\
\hline $\begin{array}{l}\text { e. Incluir los recursos provenientes de opera- } \\
\text { ciones de crédito público en ejecución, cuya } \\
\text { percepción se prevea ocurrirá en el ejercicio. }\end{array}$ & $\begin{array}{l}\text { e. Los gastos comprometidos y no devenga- } \\
\text { dos al 31 de diciembre de cada año se afecta- } \\
\text { rán automáticamente al ejercicio siguiente, } \\
\text { imputando los mismos a los créditos dispo- } \\
\text { nibles para ese ejercicio. }\end{array}$ \\
\hline
\end{tabular}

Fuente: elaboración propia con base en ley No 24.156 artículos 27 y 42.

\section{III.2. Antecedentes de reconducción en la República Argentina}

En la República Argentina la evolución de la aplicación de esta herramienta fue causa y consecuencia de desencuentros políticos. Esto no difiere mucho de los eventos que provocan el shutdown, por ejemplo, bajo la presidencia de Arturo Illia e Isabel Perón en las cuales no se consiguió que el Congreso les aprobaran su último presupuesto. Por su parte, Raúl Alfonsín finalizó su presidencia sin contar con la ley de presupuesto nacional y finalmente ese año no hubo presupuesto (1989). Distinto fue el caso de Fernando de la Rúa, quien obtuvo la sanción de la ley en marzo de 2002 totalmente modificado con relación con el proyecto original y cuando ya había dejado la presidencia (Ámbito Financiero, 2010).

El último evento de reconducción en la en la República Argentina fue en 2010 año que se activó el mecanismo de la reconducción para la Ley de Presupuesto Nacional 2011. Liberar este instituto de reconducción del Presupuesto del año 2010 para el 2011 no fue un problema para el Poder Ejecutivo, ya que tal como fuera desarrollado, el artículo 27 de la ley No 24.156 habilita al Poder Ejecutivo Nacional a continuar con la administración nacional sin tener la ley de presupuesto aprobada, aunque con límites: por ejemplo, no puede haber gastos extraordinarios, sólo lo indispensable para mantener el Estado en funcionamiento.

La peculiaridad que se produjo con esta reconducción fue que para ese ejercicio financiero (2011) comenzó a regir la reforma al artículo 42 de la Ley de Administración Financiera estableciéndose, entre otros, que los gastos comprometidos y no devengados al 31 de diciembre de cada año se afectarán automáticamente al ejercicio siguiente, imputando los mismos a los créditos disponibles para ese ejercicio. 
Fue bajo este marco legal que mediante el decreto № 2053/2010 se dispuso que a partir del 1 de enero de 2011 rijan las disposiciones de la ley No 26.546 de presupuesto general de la administración nacional para el ejercicio 2010. En tal sentido se instruyó al Jefe de Gabinete para que efectúe ajustes al Presupuesto 2010 para el próximo ejercicio, ante la falta de aprobación del correspondiente a 2011 y frente a las disposiciones de la ley No 24.156 artículos 27 y 42 citados. El propio texto del decreto No 2053 sostiene que la prórroga del presupuesto anterior vigente es una solución técnica y jurídica que salvaguarda la actividad del Estado hasta tanto se sancione una nueva ley. Por su parte, mediante el decreto № 2054/2010 se establecieron disposiciones complementarias a la prórroga del Presupuesto a fin de posibilitar la adecuada atención de distintos aspectos del funcionamiento del Estado nacional, conforme al Programa General de Gobierno.

En este contexto fueron habilitados y autorizados recursos para diversas obras de infraestructura y para ampliar redes de agua potable, cloacas, rutas, energía eléctrica, etc. En tanto, también para destinos como la represa de Yacyretá y fondos para el flamante Ministerio de Seguridad y sus correspondientes fuerzas (Policía Federal, Gendarmería y Prefectura). Asimismo, se autorizó a distintos entes nacionales a realizar operaciones de crédito público, informando al Congreso de la Nación en un plazo de 30 días y debiendo ser revisado por una comisión bicameral. En ese marco, también se autorizó a la cartera de hacienda a endeudarse por \$14.000 millones y al ministerio de Planificación por u\$s 7.600 millones de dólares. Además, se extendió el incentivo docente por otros ocho años. Por el lado de las provincias se prorrogó el pacto fiscal y habilitó a los gobiernos a endeudarse más allá del régimen de responsabilidad fiscal. Entre otras autorizaciones que también incluyo a operaciones vinculadas con el Banco Central de la República Argentina (Ámbito Financiero, 2010; decretos 2053/2010 y 2054/2010).

Consecuentemente, en la reconducción de la Ley presupuesto para el año 2011 se trató de una reconducción total y permanente, en tanto incluyó todo el período financiero para el año 2011. En tal contexto histórico, al Poder Ejecutivo le tomó la redacción de solo dos decretos para poder hacer frente a la aplicación del mecanismo bajo estudio, el cual le confirió amplias facultades a sí mismo, de disposición de la administración financiera en las que sólo debe hacer frente a los mecanismos de control presupuestario parlamentario-bicameral.

Así, se vuelve a plantear, entonces, el interrogante sentado en un principio, al considerar a la ley de presupuesto una ley formal, compleja, en donde la etapa de sanción presupuestaria constituye un verdadero acto fundamental del Congreso como plantea parte de la doctrina; o si, por el contrario, el Poder Legislativo cumple aquí un mero rol de trámite de aprobación, en cuyo caso, la falta puede ser 
rápidamente suplida/sustituida y/o reemplazada por el rol unilateral del Poder Ejecutivo.

Ante este análisis se desprende que, de tratarse de una herramienta de uso extraordinaria, la reconducción no pondría en juego el importante rol del Poder Legislativo y la etapa de sanción dentro de la dinámica del presupuesto.

Por el contrario, si esta herramienta es utilizada como un mecanismo "habitual", se tornaría en un paso meramente formal que puede derivar o no en una aprobación o no del proyecto de ley elaborado por el Poder Ejecutivo. Ello así, de tratarse de una reconducción planteada como el modelo de la República Argentina, esto es reconducción total y permanente durante el período financiero anual, la habitualidad en el uso de este instituto otorgaría al Poder Ejecutivo la facultad disponer a su gusto y capricho del diseño de las políticas financieras del Estado, sin necesidad de pasar por consenso político alguno.

Seguramente distinto sería el desarrollo del análisis si se tratara de una norma de reconducción parcial y/o temporal, en tanto la falta de aprobación del Congreso de la ley presupuestaria y la continuidad decretada en forma unilateral por el Poder Ejecutivo para ciertos programas o proyectos y /o en forma temporal, es decir, hasta lograr el acuerdo necesario en el Poder Legislativo.

\section{Shutdown}

Se ha analizado precedentemente la herramienta de la reconducción presupuestaria, por lo cual es necesario estudiar ahora otra forma casi antagónica de resolver el problema de la falta de sanción de ley presupuestaria en el tiempo oportuno.

En tal sentido se presenta el modelo del shutdown que, aplicado en materia presupuestaria, implica el cierre de la actividad financiera del Estado y por tanto el cese de actividades de la administración pública. Este mecanismo es aplicado en el momento en el que estando dentro de la etapa de sanción presupuestaria, el Congreso no logra llegar al acuerdo o consenso necesario para aprobar la ley de presupuesto. En este sentido y como sucede con la herramienta de la reconducción, se trata aquí de un mecanismo de uso excepcional y extraordinario que implica la suspensión del funcionamiento del Estado.

Escasa es la información académica que puede ser analizada a fin de lograr esbozar alguna clasificación respecto de la implementación de esta herramienta, sin embargo, del análisis histórico de la implementación del shutdown en Estados Unidos de América al menos pueden mencionarse dos modelos de cierre de la administración: shutdown total y shutdown parcial. 
Por un lado, el shutdown total o cierre de la administración pública total que consiste aplicar el cese total de actividades del Estado: oficinas públicas, todos los programas de desarrollo estatal incluso aquellos vinculados a programas sociales, salud, educación, cese de actividades vinculadas al de empleo público, programas militares entre otros. Esta fue la modalidad más utilizada en Estado Unidos al momento de implementarse esta herramienta financiera.

Por su parte, el shutdown parcial consiste en el cierre de la administración pública, excepto las actividades consideradas esenciales, como por ejemplo el servicio de correo, la seguridad social, el mantenimiento de los parques públicos por razones de turismo, algún programa militar-armada o aviación vinculado con la defensa nacional, etc. Bajo esta última modalidad, al momento de declararse el shutdown se establecen qué servicios son considerados esenciales y por tal motivo abiertos a pesar de la orden de cierre de la administración. Este mecanismo fue el último utilizado en las últimas oportunidades de shutdown producidos en la presidencia de Donald Trump en Estados Unidos.

Debe soslayarse, en definitiva, que la aplicación de cualquiera de las dos modalidades de cierre de la administración que se analizaron, el shutdown implica cierre de la administración (total o parcial) mediante una declaración unilateral del Poder Ejecutivo (tal como ha podido observarse con la reconducción presupuestaria), sin perjuicio de lo cual, esta declaración unilateral es efectuada y sostenida hasta lograr la aprobación de la ley presupuestaria (Informe Congreso Estados Unidos de América, 2018, Versión 28).

\section{Cuadro No 4. Esquema de la clasificación "Shutdown"}

\begin{tabular}{|l|l|}
\hline Shutdown parcial & $\begin{array}{l}\text { Cierre parcial de la administración pública. Se mantie- } \\
\text { nen algunos programas o áreas de urgencia activos hasta } \\
\text { la aprobación de la ley. }\end{array}$ \\
\hline Shutdown total & Cierre total de la administración pública. \\
\hline
\end{tabular}

Fuente: elaboración propia con base en Informe Congreso Estados Unidos de América, 2018, versión 28.

Tal como aconteció al analizar la reconducción, llegar a la utilización de esta herramienta es consecuencia directa de los posibles desacuerdos y posicionamientos políticos que emergen de las distintas coyunturas políticas que atraviesa cada Estado que intente generar su ley de presupuesto. O, por el contrario, no habiendo alcanzado este consenso del poder político dentro del congreso o legislaturas, en contraposición a la reconducción presupuestaria, en el shutdown no se debe seguir con la gestión de la administración financiera con lo cual se pueden vislumbrar ciertos beneficios en su aplicación. Si bien la dinámica del presupuesto es detenida hasta tanto no se logre la ley de presupuesto, lo cierto es que el 
mantenimiento de este mecanismo parece garantizar el cumplimiento de la etapa de sanción presupuestaria jerarquizando el rol del Poder Legislativo en esta etapa presupuestaria, en tanto será necesario llegar a un consenso político que obtenga el acuerdo de todos en el diseño financiero que se trata.

En países en donde la expansión del Estado no ocupa grandes dimensiones, este impasse no ofrece mayores inconvenientes en tanto garantiza una convergencia en el diseño que se pretende plasmar en la ley financiera.

En este sentido como puede verse en el análisis que se efectúa en este trabajo, el shutdown es un cierre unilateral decretado por el Poder Ejecutivo, sin embargo, evita la disposición unilateral de la actividad financiera por parte del este último poder, es decir, impide la continuidad unilateral del presupuesto.

Así al sortear el uso unilateral indiscriminado por parte del citado poder de las herramientas presupuestarias se evita la aparición de todos los mecanismos tendientes a generar ajustes discrecionales. Si bien es cierto que en algunos diseños del shutdown, previo al cierre, se prevén herramientas de prórrogas presupuestarias anteriores a las disposiciones de cese de actividades, no es menos cierto que estas prórrogas podrán ser dispuestas en tanto las condiciones financieras lo permitan, lo que implica por ejemplo que no estén agotados los recursos presupuestarios, momento en el cual esta herramienta también resulta ser obligatoria - tal como lo es la reconducción estudiada-.

En Estados en donde el desarrollo y la expansión de la actividad estatal no es amplio, en donde los fines del Estado que tiende a sustentar la ley de presupuesto se encuentra ampliamente reducidos por ejemplo a seguridad/defensa nacional, o al aporte de gestión de programas del sector privado, en donde en definitiva se encuentre retraído mayoritariamente las actividades económicas, educacionales o socio culturales, el impacto negativo resultante del cese de la administración es realmente reducido y por tanto esta herramienta no reviste mayores inconvenientes al de buscar un consenso político en una coyuntura determinada con el objeto de fijar metas presupuestarias aceptadas por la mayoría política.

Sin perjuicio de lo expuesto, este mecanismo no parece ser muy útil en Estados en donde las necesidades sociales y asistenciales son de especial relevancia tal como ocurre en los Estados emergentes en donde el cierre, incluso parcial, de la administración pública puede poner en riesgo la salud, la seguridad de la población hasta incluso la paz político social. Ello llevaría a generar un impacto negativo en los mercados y a un posible desenlace de crisis económica del sector público y privado. 
A continuación, se expone en forma esquemática las ventajas y desventajas de la implementación de:

\section{Cuadro No 5}

\begin{tabular}{|l|l|}
\hline \multicolumn{1}{|c|}{ Shutdown desventajas } & \multicolumn{1}{c|}{ Shutdown ventajas } \\
\hline $\begin{array}{l}\text { - Interrupción de la dinámica presupuesta- } \\
\text { ria: Herramienta que detiene la dinámica de } \\
\text { la actividad financiera del Estado en tanto } \\
\text { paraliza (total o parcialmente) a la adminis- } \\
\text { tración pública. }\end{array}$ & $\begin{array}{l}\text { - Jerarquización de la "ley" presupuesta- } \\
\text { ria: cobra importancia de la actividad del } \\
\text { Poder Legislativo en la etapa de sanción } \\
\text { presupuestaria. }\end{array}$ \\
\hline $\begin{array}{l}\text { - Desprotección sectores vulnerables: me- } \\
\text { canismo que no protege la conflictividad } \\
\text { social que pueden producirse por el cierre } \\
\text { de programas de contención social en países } \\
\text { emergentes. }\end{array}$ & $\begin{array}{l}\text { - Mecanismo que trata de resolver las coyun- } \\
\text { turas políticas negativas: el obligar al cierre } \\
\text { de ladministración hasta tanto se llegue a } \\
\text { un acuerdo en el Congreso, aportando apo- } \\
\text { yo y sustento político a la actividad financie- } \\
\text { ra a desarrollarse. }\end{array}$ \\
\hline $\begin{array}{l}\text { - Interrupción de la gestión financiera: no } \\
\text { permite la continuidad financiera pública. } \\
\begin{array}{l}\text { Impide al Gobierno que se encuentra gestio- } \\
\text { nando seguir con su actividad. }\end{array}\end{array}$ & $\begin{array}{l}\text { - Impide ajustes discrecionales: herramien- } \\
\text { ta que evita todo tipo de ajustes financieros } \\
\text { discrecionales y disposición de gastos y re- } \\
\text { cursos en forma unilateral por parte del Po- } \\
\text { der Ejecutivo. }\end{array}$ \\
\hline $\begin{array}{l}\text { - Cierre indefinido de la administración } \\
\text { pública: la duración de esta herramienta } \\
\text { depende exclusivamente del tiempo que se } \\
\text { tarde en lograr el consenso parlamentario, } \\
\text { en cualquiera de las dos modalidades (total } \\
\text { o parcial). }\end{array}$ & $\begin{array}{l}\text { - Herramienta de protección contra la ac- } \\
\text { tividad financiera unilateral: el Poder Eje- } \\
\text { cutivo no puede unilateralmente disponer } \\
\text { de sostenimiento de la actividad financiera } \\
\text { del Estado, protegiendo la etapa de sanción } \\
\text { presupuestaria. }\end{array}$ \\
\hline
\end{tabular}

Fuente: elaboración propia con base en Informe Congreso Estados Unidos de América, 2018, Versión 28.

\section{IV.1. El caso de Estados Unidos}

Corresponde aclarar que el período financiero establecido para el presupuesto de Estados Unidos de América no está vinculado con el año calendario, ya que el mismo se extiende desde el 1 de octubre al 30 de septiembre del año siguiente.

Con el fin de comprender cómo opera este fenómeno que involucra el cierre de la administración en Estados Unidos corresponde analizar rápidamente la etapa de sanción presupuestaria de dicho país. En ese sentido, debe soslayarse la importancia y la complejidad que adquiere en esta etapa el Congreso de los Estados Unidos, en tal sentido con la finalidad de que las agencias (organismos) y sus programas tengan presupuesto, los comités de autorización del Congreso deben aprobar y el presidente debe firmar los proyectos de autorización que dan a las agencias la autoridad legal para financiar y operar sus programas; por lo que debe 
entenderse que normalmente, una agencia, organismo o un programa no puede recibir fondos asignados anualmente sin esta autorización debida.

Esta autorización no está ligada al mismo calendario financiero público ( 1 de octubre al 30 septiembre del año siguiente) en el que se encuentra el proceso de asignaciones presupuestarias, ya que los programas pueden ser autorizados en cualquier momento del año sobre una base anual, plurianual o permanente.

En este orden de ideas resulta necesario destacar que el primer paso de la etapa de sanción presupuestaria vinculada al Congreso de los Estados Unidos de América es aprobar una resolución presupuestaria y en tal sentido son las dos cámaras del Congreso (Senado y Representantes) quienes elaboran su propia resolución presupuestaria.

Así debe mencionarse también que existe un Comité de Asignaciones de cada cámara que divide la cantidad asignada para la financiación de las agencias federales entre 12 subcomités. En tal sentido, cada subcomité se encarga de financiar diferentes funciones del gobierno como por ejemplo programa de salud, defensa, entre otros. La Cámara de Representante y el Senado llevan a votación sus proyectos de ley, si cada uno de estos proyectos es aprobado se pone a la firma del presidente. Esta etapa de sanción presupuestaria finaliza si el Congreso aprueba y el presidente firma, los 12 proyectos de ley (uno por cada subcomité) para el 30 de septiembre (el último día del año fiscal) el país tiene un nuevo presupuesto a tiempo para comenzar el año fiscal.

Sin perjuicio de lo expuesto, si el Congreso no llega a un acuerdo sobre los 12 proyectos de ley separados, puede aprobar un proyecto de ley ómnibus con fondos para múltiples áreas. Por su parte, si el presupuesto no se completa para el nuevo año fiscal, el Congreso se enfrenta a un cierre del gobierno.

Vale aclarar también, que luego del 30 de septiembre sin ley de presupuesto sancionada, el Poder Ejecutivo federal puede establecer prórrogas mensuales hasta lograr el acuerdo necesario en el Congreso para aprobar la ley de presupuesto. Esta situación a modo de ejemplo sucedió en 2018 y 2019, donde el presidente Donald Trump estableció prórrogas mensuales con anterioridad a declararse el cierre de la administración.

Consecuentemente a lo expuesto la adopción del mecanismo de shutdown resulta anormal, con base en una solución financiera temporal, hasta la finalización de la etapa de acuerdo político necesario para llegar a la aprobación en el Congreso de la ley de presupuesto. 
El marco normativo de esta medida se encuentra regulado con base en el artículo 1 sección 9 cláusula 7 del a Constitución de Estados Unidos en donde se establece que no se podrán generar gastos si no son aprobados por ley. Ello es acompañado también por la Ley de Eficacia (Antideficiency Act) y el Código de Estados Unidos título 31 (U.S. Code) entre otras normas. El alcance de la mentada norma fue entendido como sustento legal del shutdown recién en la última década por opinión de la Corte de Estados Unidos y por el departamento de justicia, concibiendo que su alcance prohíbe al gobierno Federal, autorizar gastos sin ley de presupuesto hasta incluso no aceptar servicios voluntarios ofrecidos por agentes federales por fuera de la norma presupuestaria (Informe Congreso Estados Unidos de América, 2018, Versión 28).

\section{IV.2. Antecedentes de shutdown en Estados Unidos}

Numerosos son los casos en la historia de las finanzas públicas de este país en donde se ha planteado la activación de este mecanismo en la etapa sancionatoria presupuestaria.

\section{Cuadro No 6}

\begin{tabular}{|c|c|}
\hline Año de shutdown & Presidencia \\
\hline 1976 & Gerald Ford \\
\hline 1977 & Jimmy Carter \\
\hline 1979 & Jimmy Carter \\
\hline $1981-1987$ & Ronald Reagan \\
\hline 1990 & George Busch \\
\hline 1995 & Bill Clinton \\
\hline 2013 & Obama \\
\hline 2018 & Donald Trump \\
\hline 2019 & Donald Trump \\
\hline
\end{tabular}

Fuente: elaboración propia con base en Informe del Congreso versión 28 y The Washington Post, 2013.

En el año 1976, durante la presidencia Gerald Ford duró 10 días. Le siguieron 5 cierres entre 1977 y 1979, todos ellos bajo la presidencia Jimmy Carter. Entre 1981 y 1987 la presidencia de Ronald Reagan sufrió con un total de 8, entre 1981 y 1987, ninguno superó los tres días (The Washington Post, 2013).

Durante el gobierno de George Bush (padre) tuvo lugar un cierre en el año 1990. Mientras que en la presidencia Bill Clinton se registraron dos en 1990 y 1995, este último se extendió por 21 días (The Washington Post, 2013). 
Finalmente, respecto a las últimas presidencias debe señalarse que en el año 2013 bajo la presidencia de Obama se produjo shutdown y duró 16 días. En tanto que en el año 2018 Donald Trump tuvo que afrontar su primer cierre de la administración de 3 días, y para el año 2019 el mismo mandatario registró otro cierre parcial de 107 días, este último fue levantado el 25 de enero del 2019 y es al momento, el cierre más largo de la historia de Estados Unidos de América.

Como herramienta excepcional y último recurso frente a la falta de consenso para poder lograr un acuerdo en el Congreso, parece no cumplirse en tanto 7 de los últimos 8 presidentes de ese país se vieron obligados a aplicar el mecanismo bajo análisis.

\section{IV.3. El “Estado" en Estados Unidos y los efectos del shutdown}

El impacto del shutdown debe estar enmarcado teniendo en cuenta las características propias del Estado en los Estados Unidos de América en especial, la dimensión de la administración pública.

$\mathrm{Al}$ respecto debe advertirse que la administración pública del Estado que nos ocupa, posee escasa regulación en su Carta Magna. La conformación histórica de la misma a través de las diferentes reformas fue vinculada a la actividad privada (tanto en el régimen del personal, expansión, funciones, etc.), por tal motivo se circunscribe en la actualidad al sostenimiento de parte de las fuerzas de seguridad, el sistema político (poder ejecutivo, legislativo y judicial), parques nacionales, etc.

En tal sentido debe remarcarse que la administración de este Estado no posee destinaciones presupuestarias importantes a los sistemas de educación o al sistema de salud pública. Ello en virtud que estos sectores se encuentran en manos, en su gran mayoría, del sector privado. Los trabajadores civiles (empleados públicos) de las diversas oficinas estatales son considerablemente reducidos con relación en la destinación que puede encontrarse en países como el de la República Argentina.

Consecuentemente con lo expuesto debe entenderse que el gasto del presupuesto anual de Estados Unidos cubre tres grandes áreas:

a. Gasto voluntario: es el financiamiento de las agencias federales, que el Congreso establece anualmente. El gasto discrecional suele representar alrededor de un tercio del presupuesto proyectado;

b. Gasto correspondiente a interés sobre la deuda: normalmente representa menos del 10 por ciento del presupuesto proyectado; 
c. Gasto obligatorio: es el financiamiento para el Seguro Social, Medicare, beneficios de veteranos y otros gastos requeridos por ley. Normalmente representa más de la mitad del presupuesto anual.

Ante este esquema de gastos, en el presupuesto público de Estados Unidos del año 2019 se observa un incremento del gasto en 300.000 millones de dólares. Aproximadamente el 92,5\% del déficit se produce por la reducción de tributos a empresas y a los contribuyentes de rentas más altas y que obtienen sus ingresos por medio de inversiones financieras y en el sector inmobiliario. El otro factor de aumento del déficit es el gasto en defensa asignando aproximadamente $74.000 \mathrm{mi}$ llones de dólares, reduciéndose por ejemplo la asignación para el programa Medicare (programa de salud para ciertos sectores vulnerables). Asimismo, para el programa de infraestructura se estimó una inversión de aproximadamente 200.000 millones de dólares del Estado federal. Finalmente se proyectan gastos para los programas de ayuda para la reparación de daños por huracanes para algunos Estados del país.

Consecuentemente siendo la administración pública reducida en comparación a los análisis que se pueda efectuar respecto a la administración pública como la de la República Argentina, y visto los puntos en los que se financia la administración pública estadounidense, ante la falta de este financiamiento por la no aprobación de la norma requerida, puede decirse que, a los fines prácticos, el cierre afecta a los servicios públicos y a las agencias estatales no esenciales en forma total o parcial. Todas ellas permanecen cerradas y sus empleados son temporalmente suspendidos, ya que no se les puede pagar por su trabajo. En tal sentido y a modo de ejemplo se estima que el cierre del 2018 y 2019 afectó aproximadamente unos 85.000 trabajadores del sector público federal. Esto alcanza al personal administrativo y de mantenimiento de organismos que van desde zoológicos y museos hasta agencias federales como las que regulan el alcohol, el tabaco y las armas de fuego.

\section{Cuadro No 7. Servicios que se cierran durante el shutdown}

\begin{tabular}{|l|l|}
\hline \multicolumn{1}{|c|}{$\begin{array}{c}\text { Servicios públicos afectados } \\
\text { al cierre de la administración }\end{array}$} & $\begin{array}{c}\text { Servicios públicos esenciales (que } \\
\text { pueden o no suspenderse a decisión } \\
\text { de gobierno federal) }\end{array}$ \\
\hline $\begin{array}{l}\text { Suspensión de trabajadores civiles- } \\
\text { públicos (personal administrativo) }\end{array}$ & $\begin{array}{l}\text { Servicios militares: Fuerzas Arma- } \\
\text { das, etc. (vinculado con el servicio de } \\
\text { defensa) }\end{array}$ \\
\hline $\begin{array}{l}\text { Agencias Federales de regulación (al- } \\
\text { cohol, tabaco, armamento) }\end{array}$ & $\begin{array}{l}\text { Funcionarios en servicios como avia- } \\
\text { ción, correo, seguridad social }\end{array}$ \\
\hline Servicios de recaudación tributaria & Congreso \\
\hline
\end{tabular}




\begin{tabular}{|l|l|}
\hline \multicolumn{1}{|c|}{$\begin{array}{c}\text { Servicios públicos afectados } \\
\text { al cierre de la administración }\end{array}$} & $\begin{array}{c}\text { Servicios públicos esenciales (que } \\
\text { pueden o no suspenderse a decisión } \\
\text { de gobierno federal) }\end{array}$ \\
\hline Parques públicos, museos públicos & Museos y parques públicos \\
\hline Bibliotecas nacionales & \\
\hline $\begin{array}{l}\text { Suspensión de programas presupues- } \\
\text { tarios de financiación estatal. }\end{array}$ & \\
\hline $\begin{array}{l}\text { Obra pública de financiamiento del } \\
\text { Estado Federal. }\end{array}$ & \\
\hline
\end{tabular}

Fuente: elaboración propia con base en Informe del Congreso, 2018, Versión 28.

Del cuadro efectuado precedentemente se desprende que en la mayoría de los cierres de la administración los servicios esenciales siguen siendo prestados por ejemplo incluye a las fuerzas de seguridad y a las Fuerzas Armadas, aunque ha de aclararse que sus agentes no percibirán ningún salario mientras dure el shutdown, pero igualmente deberán presentarse a trabajar. Los que también deberán asistir a sus empleos, pero sí recibirán su paga por tratarse de funcionarios civiles, son los que se desempeñan en otros sectores sensibles, como el control de la aviación comercial, la seguridad social y el correo.

Cuando el gobierno federal se queda sin fondos debido a que el Congreso no aprueba esas cuentas envía a casa a los empleados no esenciales al no poder hacer frente a sus gastos. Así, sin empleados y sin fondos, amplios sectores de la administración federal no pueden funcionar. Ahora bien, en el caso de shutdown total se cierran todos los servicios del Estado: esenciales (suspensión de trabajadores civiles, obra pública, recaudación tributaria, parques, museos etc.) y los no esenciales (fuerzas militares, servicios de aviación, postales, congreso).

Sin embargo, en el caso de los parques y monumentos nacionales en forma excepcional bajo el shutdown de Donald Trump quedaron abiertos, ya que como se expuso, el tipo de shutdown presentado por el Gobierno para dicha oportunidad fue de cierre "parcial". El impacto del uso de este mecanismo se observa fuertemente en la recaudación tributaria y la devolución de impuestos; la emisión de pasaportes y visados; y servicios militares entre otros servicios, siendo estos últimos servicios esenciales y de impacto para la población y el sector privado en general. De lo cual se desprende que el impacto del cierre de la administración no necesariamente se encuentra relacionado con los servicios esenciales que presta el Estado, ya que algunos servicios públicos pueden ser considerados esenciales conforme la coyuntura económica del momento en que se declara el cierre (por ejemplo, parques nacionales y monumentos). 


\section{Conclusión}

El análisis del último escalón de la etapa de sanción presupuestaria resultó ser un camino complejo. El principio general es que el presupuesto público es una ley, pero parecería ser que, si se está frente al modelo de herramienta de reconducción permanente y total no necesitamos de esa ley para mantener la dinámica presupuestaria.

En la República Argentina la puesta en marcha de artículo 27 y 42 siguientes, y complementarios de la Ley de Administración Financiera Nacional № 24.156 se produce cuando el Congreso no logra aprobar la ley de presupuesto antes del 31 de diciembre del año anterior a su vigencia, lo cual genera que para el año próximo inmediato la ley de presupuesto anual será la anterior, con las modificaciones que por "decreto" en forma unilateral, realice el Poder Ejecutivo, sin necesidad de llegar a un consenso o acuerdo político para logra la ley mentada.

En tal sentido parecería que el principio de legalidad requerido para la ley presupuestaria puede ser pasado por alto, aunque hay autores que agregan que este mecanismo debe ser utilizado en forma excepcional, esporádica y no como una herramienta habitual por parte del ejecutivo. Si bien la doctrina parece sentar ciertos límites razonables para avalar y sostener a la reconducción, la norma argentina nada reseña al respecto, por lo cual parecería cumplirse lo que algunos autores han entendido como la ley como una formalidad, un paso más para llegar al mentado presupuesto público y restándole importancia a la labor del Poder Legislativo en el diseño de la actividad financiera plasmada en el presupuesto público y adquiriendo de esta forma el Poder Ejecutivo todo el control en forma exclusiva respecto del diseño de la actividad financiera presupuestaria.

Por su parte, el recorrido del análisis del shutdown se presenta como una herramienta razonable, en tanto que de no llegarse a un acuerdo político se cierra la administración pública hasta tanto se logre reunir el consenso necesario, con lo cual cobra relevancia la ley como tal. Vuelve a ponerse, en primer lugar, la necesidad que el plan de actividad financiera del Estado se encuentre acordado por todos (o al menos la mayoría) de los niveles políticos del Estado, cobrando importancia, asimismo, el rol activo y necesario del Poder Legislativo en el diseño y apoyo al plan financiero del Estado.

Bajo tal análisis y sosteniendo la idea de la importancia del rol del Poder Legislativo y el mantenimiento de la necesidad de Ley presupuestaria sería razonable diseñar la aplicación de la herramienta del shutdown en cualquiera de sus modalidades, por sobre cualquier otro, en tanto es el único que, en apariencia, permitiría llegar al fin último que es la "Ley" de Presupuesto. 
Sin embargo, la implementación de un mecanismos de las características mencionadas, en países emergentes con serios problemas de pobreza, desigualdad social y volatilidad de mercados como es el caso de la República Argentina, aparejaría la generación de nuevos inconvenientes vinculados a conflictos económicos-sociales, en tanto que las dimensiones del Estado en nuestro país abarca situaciones de asistencia social, seguridad social, jubilaciones, ayuda a los sectores social y económicamente más vulnerables, empleo público, sin olvidar los fondos que se giran a las provincias en concepto de coparticipación, ni los fondos destinados a solventar servicio de la deuda; la administración pública nacional en países como el nuestro ocupa un lugar muy importante en la economía y desarrollo local. Como se pudo observar, países como Estados Unidos dedican mayoritariamente sus recursos al sector militar y el resto a programas que se sustentan en parte con el sector privado, salud y educación son aspectos solventados por el sector privado, el cierre de la administración pública no conlleva la desprotección de los sectores más vulnerables sino casi se trataría de una cuestión de pérdidas económicas en relación con la incidencia del impacto por sector.

En este orden de ideas y entendiendo que el shutdown sería de compleja instrumentación en países emergentes, no debe desecharse la idea de la implementación de instrumentos intermedios como la reconducción parcial, como la que fuera explicada en este trabajo, en la que implicaría reconducción del presupuesto, tal como lo conocemos, pero con un límite temporal fijado hasta que se genere el acuerdo político en el Congreso que pueda generar la ley de presupuesto. Así, la reconducción parcial podría ser una herramienta que vuelva a poner, en primer lugar, la necesidad de ley y el rol del Poder Legislativo en la actividad financiera pública plasmada en la ley de presupuesto.

\section{Bibliografía}

Ahumada, G. (1956). Tratado de Finanzas Públicas. Córdoba: Editorial Universidad de Córdoba.

Congreso de los Estados Unidos de América. Informe del Congreso de Estado Unidos (2018). Shutdown of the Federal Government: Causes, Processes, and Effects Updated. Congressional Research Service RL34680, VERSION 28, UPDATED. Estados Unidos de América.

Corti, H. (1997). Derecho Financiero. Buenos Aires: Abeledo Perrot.

Dalla Vía, A. (2006). Derecho constitucional económico. Buenos Aires: Lexis Nexis. 
El Sistema Presupuestario Público. Recuperado de https://www.minhacienda. gob.ar/onp/documentos/manuales/el_sistema_presupuestario_publico.pdf

Giuliani Fonrouge, C. (2011). Derecho Financiero. Buenos Aires: La Ley.

Griziotti, B. (1959). Principios de la Ciencia de las Finanzas. Buenos Aires: Depalma.

Ieral (2012). Monitor fiscal. Vol. (No 21-22). Fundación Buenos Aires. Mediterránea.

Jarach, D. (1992). Finanzas Públicas y Derecho Tributario. Buenos Aires: Ediciones Cangallo.

Las Heras, J. M. (2010). Estado Eficiente: Administración Financiera Gubernamental. Un Enfoque Sistémico. Buenos Aires: Librería Editorial.

Núñez Miñana, H. (1998). Finanzas Públicas. Buenos Aires: Ediciones Macchi.

Palacio, S. B. (2008). Finanzas Públicas: Ley de Administración Financiera. Buenos Aires: Editorial Estudio.

Ragone, S. (2014). La Administración en los EE.UU.: Un breve recorrido entre sus reformas hasta la crisis actual. ReDCE. Vol. (21).

Sleman Valdés, F. y López Lara, Álvaro, F. (2013). Los efectos de los diferentes tipos de reconducción presupuestal en las entidades federativas de México. Gestión y estrategia Vol. (No 43). México: Universidad Autónoma Metropolitana.

Fecha de recepción: 01-04-2019 Fecha de aceptación 17-09-2019 
